\title{
0 Universo Radiofônico de llhéus (BA): tênues fronteiras entre radialismo e política
}

"A neutralidade é um pecado capital. No jornalismo, na política, na vida. Lá no fundo, todo jornalismo é político..."

(trecho de artigo publicado por Eduardo

Anunciação, em O Diário do Sul, de Itabuna, em

agosto de 2000).

\section{RESUMO}

Partindo de um breve panorama traçado sobre os meios de comunicação em Ilhéus (Sul da Bahia) e o mundo político municipal, este artigo analisa as estreitas relações estabelecidas entre ambas as esferas. A perspectiva adotada é a de que entre a dinâmica cotidiana da vida política e as atividades diárias dos meios de comunicação há o estabelecimento de uma intimidade tão grande que falar do universo do rádio em Ilhéus é nesse sentido falar de algum modo de política. Assim, percebe-se como a imprensa modifica as relações das forças políticas locais e como os políticos e a mídia exercem influência mútua.

\section{PALAVRAS-CHAVE}

rádio e política

antropologia dos meios de comunicação

Ilhéus

\section{ABSTRACT}

Departing from a briefoverview on Ilhéus' mass media and on the municipal political world, this paper analyzes the close relations between both spheres. The adopted perspective is that there is an enormous intimacy between the everyday dynamic of the political life and the everyday activity of the municipal mass media to the extent that talking about radio station in Ilhéus is in some way talking about politics. Therefore, one notices how Ilhéus mass media modifies local political forces relations and how politicians and mass media influence each other.

\section{KEY WORDS}

radio stations and politics mass media anthropology Ilhéus

\section{Silvia Garcia Nogueira}

Professora do curso de Relações Internacionais UEPB/PB/BR. silvianogueira_ri@yahoo.com.br
Em Ilhéus, na "Política"', dizia-se que a prefeitura de Ilhéus dominava os meios de comunicação locais. Particularmente no que se referiu às rádios, a sensação expressa pelos ouvintes a respeito do controle sobre a informação política no município resulta de uma tendência dos discursos das elites governantes reproduzidas nos meios de comunicação. Por sua vez, tais discursos eram construídos em grande medida a partir das relações estabelecidas entre jornalistas e radialistas com essa elite.

Entre os porta-vozes desse grupo, encontrava-se a assessoria de comunicação social da prefeitura, que tinha como principal função fazer mediações entre os profissionais da imprensa e as instâncias políticas formalmente constituídas, conferindo-lhes prestígio e poder. Por meio de estratégias de difusão de seus funcionários em atividade, distribuídos em vários veículos, a representação nativa de tal domínio justificava-se em uma realidade concreta de compra de horários ${ }^{2}$ nas rádios, a realização de colunas em publicações impressas, além do envio regular de boletins para os meios de comunicação informando sobre os feitos da administração municipal.

Esse breve panorama traçado sobre os meios de comunicação em Ilhéus é resultado de um trabalho de campo realizado entre 2000 e 2002 no município, tendo por objeto de investigação o universo do rádio ${ }^{3}$. A perspectiva adotada foi a de entender o veículo não somente como um meio de comunicação de massa, mas também como um importante agente de sociabilidade local. Para isso, foram examinadas diversas esferas sociais com os quais o universo radiofônico mantém alguma interface. Entre eles, o mundo político municipal. Este se revelou como aquele com quem as relações estabelecidas são tão estreitas ${ }^{4}$ que em muitos momentos tornou-se difícil estabelecer as fronteiras simbólicas e reais entre ambos ${ }^{5}$.

Ao se adotar uma perspectiva em que o campo político local é parte da vida municipal, nota-se que entre a dinâmica cotidiana da vida política e as atividades diárias dos meios de comunicação há o estabelecimento de uma intimidade tão grande que falar do universo do rádio em Ilhéus é nesse sentido falar de algum modo de política. Assim, percebe-se como a imprensa modifica as relações das forças políticas locais e como os políticos e a mídia exercem influência mútua. A conjugação cotidiana de um universo com o outro de maneira quase indissociável é o tema deste artigo.

\section{As rádios na Política}

Os impactos do período da "Política" em Ilhéus remetem tanto aos conteúdos transmitidos nas rádios quanto, e principalmente, às relações estabelecidas e manti- 
das entre pessoas nas e a partir das emissoras. É justamente a "Política" que define a imagem que os ouvintes possuem das emissoras de modo geral. Situando-as politicamente como atreladas a grupos específicos, as rádios tendiam a ser classificadas localmente até 2004 como pertencentes a um dos dois grandes grupos: "a favor de Jabes Ribeiro" (que cumpriu o mandato de prefeito até esse ano) e "contra Jabes Ribeiro". Neste grupo, Roland Lavigne era considerado o principal opositor do então prefeito.

A estrutura de polarização entre grupos distintos na política em Ilhéus, todavia, não é recente. De acordo com um radialista e jornalista político, que acompanhou profissionalmente os acontecimentos, a situação política vem se mantendo há mais de 20 anos, dividida em dois grupos que se alternariam no poder: um grupo considerado tradicional, "de famílias com nomes tradicionais, dos coronéis de cacau", e outro, a partir de 1982, representado por um "segmento popular".

Situando as emissoras a partir do critério de identificação com um ou outro grupo ${ }^{6}$, as emissoras de rádio tendiam a colocar-se nas eleições tal como estavam dispostas as posições na esfera política eleitoral: à polarização no campo político local entre Jabes e Roland, no contexto radiofônico, correspondia à rivalidade entre $\mathrm{a}$ rádio Santa Cruz (AM) e a FM Gabriela. Em um exercício imaginário onde se possa traçar uma linha de intensidade de adesão, na qual em um pólo está a Santa Cruz com Jabes Ribeiro e no pólo oposto encontra-se a Gabriela com Roland Lavigne, as demais ${ }^{7}$ se posicionaram de modo menos rígido nesse espaço intermediário, tendendo ao pólo relacionado ao prefeito.

\section{Lógica comercial versus lógica política}

O político quer vender a imagem dele, então utiliza a mídia do rádio. Oempresário que também deveria fazer a mesma coisa para atingir a comunidade, para transformá-los em clientes, não, ele não faz. Então a gente acaba se chegando mais aos políticos, porque eles acham que têm necessidade. E eles têm razão. O que ocorre não somente no interior, mas também nas capitais. Então o político está mais presente (radialista).

As relações entre influência econômica e produção de informação vêm sendo discutidas por alguns autores há algum tempo. Bourdieu (1997) aponta os aspectos negativos da lógica comercial, que levaria a uma tentativa de despolitização dos meios de comunicação, uma vez que, como empresas, as rádios precisam sustentar-se. Tal caráter comercial das emissoras, conforme analisa Smulyan (1994), torna-as dependentes dos anúncios para sobreviverem, demonstrando o que Barbeiro (1994, p. 10) classifica como fragilidade econômica e fraqueza empresarial. A despeito dessa tendência analítica, em Ilhéus parece ocorrer justamente o contrário: os profissi- onais acreditam que a ausência dessa lógica puramente comercial é que é negativa, pois gera o que eles entendem como sendo uma politização excessiva.

Quando os anúncios comerciais são inexistentes ou escassos, as emissoras recorrem a outras fontes de recursos e a redes sociais que cumprem essa função. No município, são os políticos que preenchem, assim, a lacuna deixada pelo comércio. Desse modo, no nível das disposições em que os radialistas colocam em cheque a idéia de liberdade profissional, tanto maior ela será - pensam - quanto mais independentes dos recursos políticos forem as emissoras e os radialistas. Apesar da tensão entre o desejado apoio do comércio, de um lado, e os efetivos anúncios políticos, de outro, todos reconhecem que sem os recursos financeiros da prefeitura, ou da câmara, seria quase impossível fazer rádio em Ilhéus.

\section{As rádios e os recursos 8}

As emissoras de rádio com fins comerciais sustentam-se basicamente por meio de seus anunciantes e pelo aluguel de horários na programação, constituindo a parte comercial da rádio. Assim como em outros locais, em Ilhéus existem modalidades de formas de anunciar e de patrocinar programas: inserções de anúncios ao longo da programação (a quantidade de emissões e o tempo marcado em segundos - $7^{\prime}, 15^{\prime}, 30^{\prime}$ ou $60^{\prime}$ - variam), anúncios veiculados somente durante determinado programa ou horário, gravados por um dos locutores da emissora ou por outras pessoas, de um só dia ou ao longo de um tempo maior, além do patrocínio de um programa.

Além dos anúncios, há outras formas de captação de verbas. As emissoras vendem um espaço de tempo na programação - um horário - para alguém que queira fazer um programa ${ }^{9}$. Os valores variavam entre mil e dois mil reais, mas podiam ser negociados.

Dependendo do acordo firmado entre eles, parte da publicidade captada por aquele que compra o horário vai para a emissora e pode servir como negociação no fechamento do acordo, gerando um desconto no próprio valor pago pelo programa. Um outro tipo de negociação realizada é a de alguém ou uma instituição pagar o salário e as despesas trabalhistas do locutor, e em troca anunciar seu produto. Também é prática comum entrar nas transações comerciais o pagamento de contas como luz, telefone e materiais de consumo (fitas, canetas, blocos, etc.) da emissora tendo como contrapartida inserções de propaganda (basicamente política). Por fim, outro costume é determinar uma porcentagem das cotas de anúncios captadas individualmente pelos radialistas a ser dada para a emissora ${ }^{10}$.

Conhecendo essa política de pagamento empreendida pelas emissoras, conscientes da escassez de anúncios e preferindo investir na emissora FM líder de audiência - em que os preços além de maiores são fixos -, os comerciantes tendem a pagar os menores valores conseguidos na negociação com as rádios e os radialistas de 
AM, particularmente as de programação aberta. Desse modo, mesmo o que poderia ser enquadrado sob o rótulo de "relação comercia" ganha tons pessoalizados.

Assim, o que, na perspectiva dos radialistas, deveria ser visto pelos comerciantes como um investimento, é visto por eles como um gasto. O que deveria ser encarado como uma troca de serviços é lido como uma ajuda. No plano mais concreto desse processo de captação de anúncios, independente do sentido simbólico que ganhe, a falta de anúncios geralmente implica - nos casos em que isso compõe o salário recebido da emissora - um pagamento menor do que o devido. Nas emissoras que utilizam essa forma de pagamento, com uma parte fixa e outra flutuante, faz parte do ritual diário a saída para visitação do comércio local fora do horário de trabalho com esse objetivo. Quando é bem-sucedido, o radialista tem seu salário integral; quando não, recebe apenas o fixo (geralmente um salário mínimo).

Com a "falta de investimento do comércio", segundo se diz no meio, excetuando-se a Gabriela FM ${ }^{11}$, todas as outras emissoras de rádio têm como importante anunciante a prefeitura e a Câmara de Vereadores. A injeção financeira dos recursos municipais é feita pela veiculação direta de anúncios institucionais, pela compra de programas por "gente da prefeitura"12 e, em ano eleitoral, pelo aluguel de uma parte do horário da programação de algumas rádios (em 2000, a Cultura, a Novo Tempo e a Santa Cruz; em 2002, a Cultura, a Baiana, a Santa Cruz e a Gabriela) para a transmissão em rede de um programa semanal dedicado a notícias relativas à administração municipal. Em 2000, outro programa dedicava-se a assuntos de saúde no município, sob o comando da Secretaria de Saúde.

Certo mesmo é prefeitura, Câmara, Secretaria. De despesa, 10 mil para tudo. $O$ faturamento é grande. Perto de eleição vem uma cacetada. Rádio é bom negócio. [Para você não seria interessante vender todos os horários?] Eu não posso pela minha política. Perco o dinheirinho certo. O ideal seria colocar todos os partidos aqui. Mas aí não quer, né? [E os funcionários que são da prefeitura?] Eles recebem lá e recebem aqui.

O "dinheirinho certo", conforme o dono de uma rádio, portanto, é que faz da atividade "um bom negócio". É ele, também, que determina a política e a linha editorial, orientando sobre o que pode ou não ser dito, quem pode ou não participar de alguns programas como convidados, enfim para o quê e para quem se abrem os microfones. Contudo, se estar na política, em período eleitoral, ou fora dela, faz variar "o dinheirinho certo", a liberdade dos microfones também varia em grau em função do período. Na Política, a presença no ar e o controle sobre as emissoras são maiores, inclusive com o acompanhamento da programação por pessoas dos diversos grupos políticos que ouvem tudo o que é transmitido. Em com- pensação, o "dinheirinho" também é maior tanto para as emissoras quanto para os radialistas individualmente que recebem as cotas. Além disso, os profissionais do rádio são chamados para apresentarem comícios, showmícios, fazerem gravações para o horário eleitoral gratuito $^{13}$ ou de propaganda veiculada em carros de som que circulam pelo município. Fora da Política, tem-se mais liberdade, menos recursos políticos e menos oportunidades de trabalhos extras.

\section{A ASCOM e a Dependência Informacional}

Além da dependência econômica alimentada pelos agentes políticos, estes buscam estabelecer estrategicamente outro tipo de dominação sobre os meios de comunicação, a partir da criação de uma dependência informacional. Nesse sentido, pode-se dizer que a relação entre fontes e profissionais da informação em Ilhéus constróise a partir da dependência mútua.

Quando ocorre um atraso nas entregas dos jornais regionais e dos informativos da Prefeitura e da Câmara de Vereadores, os radialistas de programas jornalísticos no rádio ficam ansiosos com a chegada dos assuntos que sofrerão pequenas adaptações para a linguagem radiofônica e serão lidos. Para que os políticos, por intermédio de suas assessorias de comunicação social, exerçam um desejado domínio dos meios de comunicação locais, acredita-se ser preciso transmitir constantemente informações selecionadas, com enfoques que obedeçam a interesses particulares.

"Aqui nós trabalhamos como na empresa privada: o que importa é a satisfação do cliente. Se a gente não tem o que a pessoa quer, a gente resolve. A pessoa não sai daqui sem uma solução." Essa declaração dada por um jornalista da assessoria de comunicação social (ASCOM) da prefeitura poderia ter sido feita por um radialista de uma emissora AM. Eles entendem que a satisfação do cliente é que torna suas atividades legitimamente bemsucedidas. Se para os radialistas, o atendimento às demandas dos que os procuram é percebido como a realização de um trabalho social, para os funcionários da assessoria de comunicação buscar soluções faz parte do próprio exercício profissional. Todos sentem que ao fazerem isso, estão cumprindo um dever.

Paralelamente ao atendimento prestado àqueles que os procuram, os profissionais dizem ter um outro tipo de orientação fundamental ao desempenho das suas atividades: informar. "Nós temos uma política muito clara: nosso material não é promocional, mas informativo dos atos do prefeito. A idéia dele é democratizar a informação", explica um jornalista da assessoria de comunicação. Essa política de democratização da informação corresponde a uma série de medidas regulares adotadas: produção diária do Boletim de Notícias, um informativo distribuído diariamente para os órgãos de comunicação e para os jornalistas da região; realização de fotos de eventos de interesse da prefeitura para serem distribuídas para os veículos de comunicação; atendimentos e 
encaminhamentos para setores e pessoas que possam fornecer as informações solicitadas; produção de programas de rádio sobre assuntos relacionados de alguma forma à administração municipal.

Para realizar todas as tarefas, a ASCOM contava com cinco jornalistas e dois radialistas, além do setor de fotografia. Alguns dos profissionais são funcionários públicos, outros são contratados como prestadores de serviços. O número de pessoas que trabalha na assessoria é, porém, flutuante, uma vez que contratações e dispensas são feitas de acordo com as necessidades impostas pelas tarefas a serem desenvolvidas e os objetivos a serem alcançados. Durante o período eleitoral, a assessoria tende a contratar mais gente para atender às exigências de campanha.

Em 2002, um programa de rádio transmitido em cadeia às 13 horas com duração de 15 minutos envolvia o assessor de imprensa como editor, mais oito pessoas (dois repórteres, três locutores e o pessoal da técnica). Diferentemente do programa realizado em 2000, o formato seguia um modelo mais próximo dos programas de variedades das emissoras AM abertas. Era composto por musical, vinhetas, chamadas, comerciais da prefeitura e notícias que não são da prefeitura, destaques dos jornais (menos os de oposição), matérias com participação da população e comentários oficiais sobre os temas abordados. Esse programa gerou críticas de alguns radialistas que, acostumados a um determinado padrão de programa realizado pela prefeitura, declaradamente com conteúdos oficiais, não gostaram do novo formato. Um deles disse, na ocasião do lançamento, que assim “o programa está mascarado...se é pra ser um programa oficial, tudo bem, mas assim está mascarado."

A tensão gerada pela compreensão do que seja aquilo que é definido como uma ação "mascarada" e uma ação "oficial" corresponde a duas óticas diferentes de percepção, na rede, de como deve ser a relação entre seus interlocutores e os limites das representações de como cada um deve desempenhar seu ofício. Nesse caso, um programa "mascarado" é aquele que parece não ser "oficial", sendo. Ser "oficial", por sua vez, é ser facilmente identificado por todos como comprometido com uma determinada visão interessada dos fatos. Desse modo, partindo do pressuposto de que em certa medida ao se fazer rádio em Ilhéus se faz política, o "mascaramento" de um conteúdo repleto de interesses políticos e a suposta neutralidade jornalística - o pecado capital de que falava Anunciação em seu artigo, na epígrafe deste artigo - são estranhos ao próprio desenvolvimento das atividades profissionais, constituintes dessa rede de relações entre radialistas/jornalistas-políticos-população.

O que se espera, então, dos profissionais da ASCOM é que gerem discursos oficiais, pois essa é, em última instância, sua própria razão de existência. É isso também que diferencia o modo como jornalistas e radialistas percebem o desempenho de suas atividades, mesmo conscientes de que, na prática, ocorra uma continuidade entre o que eles fazem e o que os profissionais da ASCOM fazem.

Nesse jogo de diferenciações e identificações mútuas, os profissionais da ASCOM entendem, como já foi dito, que suas ações democratizam a informação - portanto "democracia" ganha significados positivos relacionados à extensão de alcance, à quantidade de pessoas que pode atingir. E uma das maneiras pelas quais a democratização torna-se viável é pela utilização da estratégia de tornar-se fonte principal dos meios de comunicação regionais.

Para os radialistas, ao contrário, ter a assessoria de comunicação da prefeitura como a principal fonte de informação é sentido como algo inevitável, não necessariamente desejável, devido às condições de trabalho a que estão submetidos. Sendo assim, a propalada "democratização da informação" relaciona-se, para eles, à idéia de liberdade para apresentar diferentes tipos e abordagens da informação - portanto referentes a aspectos qualitativos da difusão de informações. Esse intervalo entre uma e outra percepção explica, pois, que as ações realizadas pela assessoria sejam percebidas, de um lado, como atividades de democratização da informação, e, de outro, como atividades de dominação dos meios de comunicação.

\section{Considerações finais: Radialista ou político?}

Em um universo marcado pelo pertencimento a uma mesma rede de relações, onde as atividades profissionais de seus componentes em muitos momentos se confundem - com políticos que fazem política usando a rádio e radialista que fazem rádio e política -, as fronteiras entre uma e outra atividade são quase imperceptíveis. Pode-se dizer que na prática cotidiana de um e outro grupo, o que diferencia suas atividades nessas ocasiões são justamente os aspectos formais que envolvem a definição e a auto-representação do que cada um é: os radialistas utilizam-se de um saber-fazer próprio, possuem status específico e exercem a profissão porque possuem uma licença para isso, o DRT; aos políticos, nada disso é exigido quando estão no ar, portanto seus compromissos são com seus interesses.

Uma outra diferenciação entre eles é a clareza que possuem de que se os políticos estão sempre fazendo política - entendida como atividades realizadas pelos políticos no exercício de suas funções -, os radialistas nem sempre estão. De modo geral, para eles, a consciência de que ao fazerem rádio fazem também política está relacionada à idéia de que isso tende a ocorrer, de modo inevitável, durante o período eleitoral. Falar de assuntos considerados políticos durante a Política implica para eles necessariamente posicionar-se politicamente em relação aos assuntos ${ }^{14}$. Obviamente, tais posicionamentos não são homogêneos nem em relação à intensidade de adesão nem em relação às posições adotadas. Há uma grande variedade de possibilidades que depende das escolhas individuais dos radialistas e das orientações 
políticas das emissoras. Além disso, as emissoras AM não religiosas tendem a se posicionar mais afirmativamente frente a essas questões políticas do que as religiosas e a FM.

Gabriela Scotto, em seu trabalho sobre marketing político (2003), estabelece uma discussão acerca da política como uma atividade permanente ou ocasional. Para tal, baseando-se em Weber (1979) e Gaxie (1978), apresenta classificações dos níveis de profissionalização que definiriam as fronteiras entre os profissionais envolvidos na política como uma atividade. Nesse sentido, haveria uma gradação em função do tipo de ligação financeira, do vínculo emocional e da dedicação de tempo à atividade: há os que fazem da política uma atividade integral, onde a política é o conteúdo da existência, pois vivem para a política (estes seriam os "profissionais da política"), e há os que fazem da política uma profissão secundária ou ocasional (Scotto, 2003, pp. 275-277). Os políticos de Ilhéus seriam os profissionais da política - a assessoria de comunicação social estaria também neste grupo - e os radialistas, a princípio, estabeleceriam uma relação secundária ou ocasional.

Embora o termo "marketing político" não tenha sido ouvido em nenhum momento no universo estudado, é possível estabelecer uma proximidade entre os "marqueteiros" de que fala Scotto e os radialistas em Ilhéus. No período eleitoral, todos estão voltados para isso; fora da Política, tanto quanto os "marqueteiros", as relações dos profissionais com a Política varia muito. A proximidade justifica-se na medida em que do grupo estudado pela autora fazem parte jornalistas de meios impressos e televisão, e radialistas que por suas aptidões e técnicas são qualificados para fazer "marketing" para os candidatos. Seus conhecimentos profissionais são valorizados, e a eles é atribuída grande parte do sucesso na política: sabem se comunicar com o público, dominando a "palavra falada e a boa imagem" (Scotto, 2003, pp. 232-233).

Uma opção real de trabalho paralelo desenvolvido pelos radialistas, na esfera política, é a de profissional de assessoria de imprensa de um vereador. De modo geral, esse cargo de confiança é oferecido naturalmente com a vitória do candidato para aqueles que fizeram campanha e prestaram serviços antes das eleições. O pertencimento a um grupo político na Câmara Municipal, no poder legislativo, no entanto, não constrói necessariamente uma linha de continuidade de adesão destes profissionais no nível executivo.

Para eles, de modo geral, há separações entre o que seria uma adesão ideológica, uma adesão pessoal e uma adesão profissional. Fazem também uma distinção entre as relações que desenvolvem com o universo em torno da Câmara Municipal e com o universo em torno da Prefeitura. Os compromissos (profissionais, pessoais, ideológicos) assumidos em um deles não implicam necessariamente nos compromissos assumidos com o outro. Apresenta-se, desse modo, um amplo leque de com- binações possíveis em termos de apoios, adesões e prestações de serviços.

Por adesão ideológica, os radialistas entendem que compartilham com os escolhidos determinados valores e práticas dentro do que percebem como sendo a conduta ideal de um político no exercício de seu ofício como tal. Relaciona-se às idéias de escolha, de opção consciente, por acreditarem nas qualidades políticas daquele candidato, vereador ou prefeito.

A adesão pessoal é aventada por meio de argumentos que giram em torno de qualidades pessoais, carismáticas, remetendo ao que o candidato, vereador ou prefeito é como pessoa ${ }^{15}$. São julgadas, então, para uma tomada de posicionamento, as qualidades percebidas nas diversas atuações realizadas na rede de relações pessoais de amizade, geralmente prévias ou paralelas às redes políticas de poder no município.

Um terceiro tipo de justificativa de adesão levantada diz respeito àqueles argumentos que, ao contrário dos demais, identificados por eles como dotadas de emoções e sentimentos, remete a questões objetivas e frias: prestar um serviço profissional e ser pago por isso.

Há um pequeno grupo de radialistas que em determinados momentos de suas carreiras pensam em abandoná-las - definitivamente ou temporariamente - para seguir o que sentem como um caminho quase natural: entrar para a política. No discurso daqueles que realizaram essa empreitada, candidatando-se ou desejando se candidatar a um cargo político eletivo, a justificativa é o atendimento a uma cobrança, a uma exigência, do povo (a população, os ouvintes). Segundo eles, é o "trabalho social" que desenvolvem como radialistas que os credencia para entrar na disputa política.

Os radialistas, em suas candidaturas, procuram levar, então, para o âmbito político, características e elementos encontrados nos limites de seus exercícios profissionais. A razão disso é o entendimento de que foi por meio do desempenho profissional e da popularidade alcançada que se tornaram qualificados para a entrada na política. Esta só ocorreu em função do chamamento de seus ouvintes e do reconhecimento de grupos políticos dessas credenciais.

Ao lado dos argumentos levantados para a justificação da candidatura de um radialista em Ilhéus, há um repertório tão significativo quanto de argumentos contrários. Um deles é o de que a popularidade alcançada como radialista não é revertida automaticamente em popularidade para a candidatura política do radialista, como dizem os que pensam de modo oposto. Segundo eles, a popularidade que obtêm no desempenho de suas atividades no rádio pode ser utilizada a favor de um candidato, mas não para eles mesmos. Estes tendem a separar o exercício profissional como radialistas das atividades desenvolvidas como políticos tanto quanto distinguem os atributos necessários para o exercício de um e de outro papel social.

Uma máxima local entre esse grupo de radialistas é 
que eles elegem candidatos, trazendo votos para os apoiados por eles, mas não conseguem se eleger. Portanto, os capitais simbólicos dos quais são detentores não são transferíveis para outras esferas sociais que não o universo do rádio.

Assim como no caso do grupo de radialistas que citam exemplos de sucessos nessa empreitada de passagem, esses radialistas mais descrentes citam também diversos casos locais de fracassos eleitorais afamecos

\section{NOTAS}

1 Trata-se do período eleitoral, neste caso, relativo às eleições municipais, entre julho e outubro. Durante esse "tempo da política" (Palmeira, Heredia, 1993), ou da Política, termo local, é possível perceber claramente as adesões das emissoras e dos radialistas a grupos políticos específicos, por meio dos conteúdos veiculados, dos programas comprados por políticos e pelos adereços utilizados pelos radialistas nas rádios. Ao lado da Política, outros períodos temporais marcam a vida social local: o Verão e o São João (Nogueira, 2005).

2 Toda vez que neste texto aparecer palavra, expressão ou frases em itálico significa que corresponde a um termo nativo. A referência local ao pagamento pela utilização de um período de tempo da programação das emissoras pode ser compra de horário, aluguel de horário ou arrendamento do horário. O termo horário pode ser substituído por programa.

3 A pesquisa resultou na tese de doutorado intitulada Facetas do Rádio: Uma Etnografia das Emissoras de Ilhéus (Sul da Bahia), defendida no Programa de Pós-Graduação em Antropologia Social do Museu Nacional, Universidade Federal do Rio de Janeiro, em 2005. As relações entre política e rádio em Ilhéus também foram discutidas em um trabalho anterior (Nogueira, 2007).

4 Longe de parecer ser um fenômeno específico referente a Ilhéus, ao lado, na vizinha Itabuna, essa é também uma característica das emissoras locais.

5 Como é de praxe na pesquisa antropológica com abordagem etnográfica, não cabe ao analista tecer nenhum juízo de valor sobre as práticas sociais empreendidas. As situações aqui expostas baseiam-se em depoimentos formais e informais, e na vivência cotidiana no universo radiofônico, bem como nas interpretações que os atores sociais possuem sobre suas práticas. Sendo assim, não coube neste trabalho verificar a veracidade dos fatos apresentados pelos informantes, mas apresentar suas visões sobre o universo do qual fazem parte.
6 É preciso enfatizar que essa é uma representação local. Efetivamente, a influência da administração municipal nas emissoras varia de rádio para rádio, e de acordo com estratégias políticas dos donos e radialistas, e da prefeitura.

7 Além da Santa Cruz e da Gabriela, as outras emissoras locais são a Novo Tempo (AM), que deu lugar entre 2000 e 2002 à Rádio Baiana (AM); a Cultura (AM), pertencente à Igreja Universal do Reino de Deus (IURD); e a Cidade (FM), também da IURD, mas sem programação local.

8 Os dados a respeito dos recursos recebidos aqui apresentados possuem um caráter representacional, baseando-se em percepções nativas e interpretações da realidade vivida.

9 Os valores variavam entre mil e dois mil reais, mas podiam ser negociados.

10 A captação dos anúncios pode ser realizada diretamente pela emissora - que determinará as inserções comerciais distribuídas ao longo da programação, ou em horários e programas específicos - e por cada radialista ou pessoa que compra o horário (respeitando o limite acordado com a emissora), que geralmente dá parte do arrecadado à rádio (variando de emissora a emissora, ou do acordo feito com o radialista).

11 A liderança de audiência é um atrativo para o comércio anunciar na emissora. Além disso, é preciso considerar que a rádio pertence a um próspero empresário, que integra a Junta Comercial de Ilhéus, do qual participam outros empresários com os quais mantém relações.

12 Por "gente da prefeitura" os radialistas estão se referindo a funcionários contratados ou concursados pela administração municipal ou radialistas que recebem remuneração extra da prefeitura.

13 Em 30 minutos de programação diária de todas as emissoras, no período eleitoral, as inserções políticas obrigatórias estavam assim distribuídas: PSDB (20), PFL (18) e PT (10). Nas rádios, os partidos mandavam representantes entregarem emedês contendo o material a ser divulgado. Os partidos escolhem a faixa de horário em que deverão ser feitas as inserções, e as emissoras escolhem os horários precisos. A não execução implica em multas por descumprimento de determinação da justiça eleitoral.

14 Obviamente, tais posicionamentos não são, homogê- 
neos em relação a intensidade da adesão nem em relação as posições adotadas. Há uma grande variedade de possibilidades que depende das escolhas individuais dos radialistas e das orientações políticas das emissoras. Além disso, as emissoras AM não religiosas tendem a se posicionar mais afirmativamente frente a essas questões políticas do que as religiosas e a FM.

15 Pessoa ganha, nesse contexto, um sentido diverso com o que o candidato, vereador ou prefeito é como político. Isso significa que o que está sendo avaliado é o traço de caráter e seu jeito de ser e viver fora do que os radialistas percebem como sendo a esfera política (na qual desempenham as atribuições como políticos). Para uma discussão mais ampla sobre o assunto referido a outro contexto, ver Chaves (2000).

\section{REFERÊNCIAS}

BARBEIRO, Heródoto. "O Radiojornalismo Renovado". In: KAPLAN, Sheila; REZENDE, Sidney (Orgs.), Jornalismo Eletrônico ao Vivo. Petrópolis: Vozes, 1994.

BOURDIEU, Pierre. Sobre a Televisão. Rio de Janeiro: Jorge Zahar Editor, 1997.

CHAGAS, Miriam de Fátima. Uma Mão Lava a Outra: A Interação de Grupos Populares com a Rádio Farroupilha. PPGAS/UFRS (Dissertação de Mestrado), 1993.

CHAVES, Christine Alencar. A Marcha Nacional dos SemTerra: Um Ensaio sobre a Fabricação do Social. Rio de Janeiro: Relume-Dumará, 2000.

GAXIE, Daniel. Le Cens Caché. Inegalités Culturelles et Ségrégation Politique. Paris: Édition du Seuil, 1978.

GOLDMAN, Marcio. “Segmentaridades e Movimentos Negros nas Eleições de Ilhéus". Mana. Estudos de Antropologia Social, vol.7, n.2, pp. 57-94. 2001.

“Uma Teoria Etnográfica da Democracia. A Política do Ponto de Vista do Movimento Negro de Ilhéus, Bahia, Brasil". Etnográfica, vol.4, n.2, pp.311332. 2000.

GÓMEZ, Hérnan E. Las Notícias como Ámbitos de Construcción de Hegemonia Discursiva. Comunicação $\mathcal{E}$ Política n. IV, vol.1, nova série, 1997.

KUSCHNIR, Karina. O Cotidiano da Politica. Rio de Janeiro: Jorge Zahar Editor, 2000.

MACUNANE, José Jaime. “Nas Entrelinhas da Notícia: Democracia, Narrativa e Conflito Político nas Pági- nas do 'Savana' e 'Domingo'”'. Travessia n. 1, pp. 3956. 1999.

MIGUEL, Luis Felipe. Política e Mídia no Brasil, Episódios da História Recente. Brasília-DF: Editora Plano, 2002.

NOGUEIRA, Silvia Garcia. “As Rádios, Os Políticos e a Política: uma Relação Íntima no Interior Baiano". Intercom-RBCC, v.30,n.2, julho/dezembro 2007.

. "Facetas do Rádio: Uma Etnografia das Emissoras de Rádio em Ilhéus (Sul da Bahia). PPGAS/Museu Nacional/UFRJ, Tese de Doutorado, 2005.

PALMEIRA, Moacir; HEREDIA, Beatriz. Le Temps da La Politique. Études Rurales, n.131-132, pp. 73-88. 1993.

SCOTTO, Maria Gabriela. As (Difusas) Fronteiras entre a Politica e o Mercado. Um Estudo Antropológico sobre Marketing Político, seus Agentes, Práticas e Representações. PPGAS/Museu Nacional/UFRJ (Tese de Doutorado), 2003.

SMULYAN, Susan. Selling Radio. The Commercialization of American Broadcasting, 1920-1934. Washington: Smithsonian Institution Press, 1994.

SOLOSKI, John. "O Jornalismo e o Profissionalismo: Alguns Constrangimentos no Trabalho Jornalístico". In: Nelson Traquina (org.), Jornalismo: Questões, Teoria e "Estórias". Lisboa: Veja, 1993.

WEBER, Max. A Política como Vocação. Lisboa: Editorial Presença, 1979. 